\title{
Una política municipal para el desarrollo de la Micro, Pequeña y Mediana Empresa
}

Tarapuez Chamorro, Edwin*

\section{Resumen}

En los últimos años se ha vislumbrado un nuevo paradigma del desarollo regional en el que las variables que más interesan son las científico-tecnológicas, el medio ambiente, la descentralización y la creación de micro, pequeñas y medianas empresas (MIPYMES). En este nuevo escenario cobra especial importancia el empresario schumpetenano, innovador y competitivo, con arraigada identidad local y regional. Con el fin de dejar atrás los programas aislados de apoyo al sector empresarial, el gobiemo colombiano aprobó la Ley 590 de 2000, más conocida como la "Ley MIPYME", que se constituye en la columna vertebral de la política del Estado colombiano para el apoyo integral de dicho sector. A pesar de ello aún se necesitan políticas municipales para articular los esfuerzos locales con los nacionales. El autor propone cinco componentes básicos de una política municipal para el desarrollo de las MIPYMES: ambiental, capacitación, comercialización, financiamiento e impuestos municipales (el componente tecnológico se incluye en cada uno de los anteriores), coordinados por una Secretaría Municipal de Fomento y Competitividad Empresarial, como ente articulador de todos los componentes e interlocutor directo entre el gobiemo municipal y los empresarios del municipio. La propuesta fue elaborada para el Municipio de Pasto (Colombia) pero contiene elementos de análisis útiles para cualquier municipio.

Palabras clave: Politica Municipal, Desarrollo Económico, Desarrollo Regional, PYME.

\section{Municipal Policy in the Development of Micro, Small and Médium Sized Business Firms}

\section{Abstract}

Over the last years a new paradigm of regional development has arisen in which the most important variables are science-technology, environment, decentralization, and the development of micro, small and medium sized business firms (MIPYMES). In this new vision, the Schumpertonian businessman, innovative and competitive, and with a local or regional identity, has received special at-

Recibido: 01-05-14. Aceptado: 01-07-27

Vicerrector Académico del Centro de Estudios Superiores María Goretti. Pasto, Nariño. Colombia. Email: goretti@ cesmag.edu.co 
Política municipal para el desarrollo de la Micro, Pequeña y Mediana Empresa Tarapuez Chamorro, Edwin

tention. In the interest of leaving behind isolated support programs in the business sector, the Colombian government passed law 590 in the year 2000 , better known as the MIPYME Law, which became the vertebra of Colombian State policy in order to integrate this sector. In spite of this, municipal policies are also needed to articulate local and national efforts. The author proposes five basic components for municipal policy in order to develop MIPYMES: environment, training, commercialization, financing, and municipal taxation (the technological component is included in each), all of which are coordinated by a Municipal Office (secretary) for the Development of Business Competitiveness, which would be the integrative unit and the interlocutor between the municipal government and the municipally based business firms. The proposal was developed for the Pasta Municipality (Colombia) but has analytical elements which could be useful in any municipality.

Key words: Economic development, regional development, PYME.

\section{Introducción}

El tema del desarrollo regional es relativamente nuevo $y$ ha generado mucho interés entre los diferentes actores sociales que han aportado distintos puntos de vista, enfoques y propuestas a través de los cuales se ha tratado de explicary orientar la evolución de las regiones.

En las décadas de los treinta y los cuarenta se pensó que la configuración del mercado nacional haría posible el desarrollo armónico de las regiones de los paises de América Latina. De igual manera en los años cincuenta y sesenta se pensaba que el comercio internacional, con base en una nueva división del trabajo por sustitución de importaciones, resolvería las crecientes diferencias del desarrollo tanto entre las naciones como entre las regiones de los países.

Lo cierto es que en los últimos años se ha puesto de manifiesto que en los mercados nacionales conviven regiones superdesarrolladas e infradesarrolladas. En este sentido, el centralismo trajo como consecuencia el favorecimiento de zonas particulares, como ciudades capitales, las áreas metropolitanas que representa- ban una posición financiera e industrial crucial, o las que tendrían un papel estratégico en el proceso de unificación nacional. De ahí que se afirme comúnmente que las cabezas de centralización financiera $e$ industrial son los factores de origen del subdesarrollo regional (Molina, 1997: 935-936).

\section{El Desarrollo Regional}

Se ha hablado de varios modelos de desarrollo regional, entre ellos, el Desarrollo integrado de las cuencas hidrográficas, el de estrategias de regionalización y de creación de polos de desarrollo, el de estrategias de desarrollo rural integrado, el modelo neoclásico, la corriente regional participativa y últimamente se ha hablado de un modelo de desarrollo territorial, más asociado con la gestión empresarial y con la búsqueda de la competitividad.

De acuerdo con Sili (1997:460463), a principios de los años noventa comenzó a vislumbrarse este nuevo paradigma. Los temas que ahora interesan son las políticas cientifico-tecnológicas, el medio ambiente, la descentralización y 
la creación de micro, pequeñas y medianas empresas (MIPYMES). En este nuevo escenario cobra especial importancia el empresario schumpeteriano, innovador y competitivo, con arraigada identidad local y regional.

Crecimiento y desarrollo económicos entrañan la noción común de un aumento en el nivel de vida de la población de una región o territorio, por lo que en ocasiones estos dos términos se usan indistintamente. Sin embargo, el crecimiento económico suele tener una connotación más cuantitativa al utilizar indicadores como el PIB per cápita, el consumo real promedio o el valor agregado por unidad de trabajo, entre otros, para registrar en el tiempo los incrementos productivos de una economía.

Teniendo en cuenta que el problema de los países más atrasados no es simplemente crecer, pues experimentan incrementos productivos cíclicos de diversa magnitud, se puede hacer otra distinción sencilla entre crecimiento y desarrollo. El primero sería un processo propio de economías desarrolladas, en que la existencia de capital y progreso tecnológico contrasta con lo que ocurre en países menos avanzados, donde muchos problemas provienen de la insuficiencia de dichos factores y cuya creación es un problema fundamental. Los procesos más complejos y menos conocidos que permiten el crecimiento económico de los países subdesarrollados pueden considerarse como el contenido del desarrollo.

Ahora bien, desarrollo y subdesarrollo son categorías históricas relativas. Un país o una región tiene una u otra relación con más naciones o regiones (Ramirez, 1997:474).
La palabra región proviene del latín regere que significa linea, demarcación. Por extensión se interpretaría como el territorio comprendido entre varias líneas de demarcación. Así es la unidad o porción de superficie inmediatamente menor que la unidad nacional cuyas características o propiedades socioeconómicas y socioculturales le determinan una identidad económica y socialmente significativa en el conjunto nacional.

En planeación, la región constituye la inclusión del elemento espacio en los objetivos y metas y constituye una estructura dependiente. En economía internacional una región puede significar un grupo de naciones.

En muchas ocasiones, sin embargo, no ha existido la suficiente claridad sobre el concepto de región y se le ha dado a éste diferentes connotaciones de acuerdo al punto de vista del autor.

Es conveniente aclarar consecuentemente que el desarrollo se refiere a cambios inducidos en forma consciente $e$ intencional, a través de políticas que en forma deliberada son impulsadas por diferentes agentes del desarrollo, de lo cual se infiere que el desarrollo es un proceso colectivo y dinámico que no se realiza en forma aislada y en el cual también influyen los cambios generados desde y hacia el interior de la región.

En este sentido, el desarrollo regional se diferencia del desarrollo económico en que el primero incluye el espacio fisico (la región) como un componente fundamental de su análisis, aunque en muchos casos el referente territorial pasa a un segundo lugar ya que se privilegian los procesos y los actores y no los espacios, signo evidente de la globalización y la 
desterritorialización de los procesos económicos y sociales.

De esta manera el desarrollo económico regional puede describirse como una serie de incrementos en el volumen de las operaciones económicas, es decir, en el producto agregado y en el ingreso total, entendidos éstos como la suma del valor de lo producido en las diferentes actividades económicas -ya sean industriales, agrícolas o de servicios-, y como la suma total de los ingresos generados para quienes participan en esas actividades, como empresarios, trabajadores o empleados (Rangel, 1993: 22-25).

Si se realiza un análisis más detallado, el desarrollo económico, en general, es un proceso que persigue, entre otros, los siguientes objetivos (Varela, 1998: 40-41): Incremento del PIB per cápita, mejora en la distribución de la riqueza, los niveles de igualdad y oportunidad social, balanza de pagos positiva, estabilidad de precios, incremento del número de puestos de trabajo, disminución del desempleo y subempleo, crecimiento de la participación popular en la vida política y económica, paz, ambiente social sano y autorrealización.

Dentro de los principales actores sociales del desarrollo regional se encuentra, desde luego, el Estado, principal impulsor del crecimiento económico regional que no sólo es la instancia que asigna y controla la inversión, sino que además es la que debe garantizar el desarrollo equitativo de las regiones, en el marco de unas políticas nacionales a las cuales debe articular el desarrollo regional y local.

Pero no basta con la presencia del Estado y la financiación, ellos por sí solos no conducen al desarrollo, la sociedad regional es sin duda el segundo actor clave del desarrollo regional, sin la cual éste no sería viable ni contribuiría a la interrelación de las políticas en los diferentes niveles. Podría entonces señalarse que la sociedad es la gestora de su propio desarrollo (León, 1997: 40).

Dentro de este contexto regional, el municipio debe ser un generador de oportunidades para los habitantes de su zona geográfica. Su función, en este sentido, se orienta a articular estrategias de desarrollo que se traduzcan en acciones que beneficien a la comunidad en su conjunto.

Para generar oportunidades es necesario elaborar estrategias de desarrollo con el fin de optimizar el uso de las potencialidades existentes, aumentar las fortalezas locales y procurar el desarrollo equilibrado del municipio. $Y$ eso requiere definir objetivos claros y consensuados, para lo cual es necesario articular a los agentes de desarrollo presentes en el municipio, establecer relaciones de colaboración con el sector privado y coordinarse con otros municipios, el departamento, la región y el gobierno central. Así como una nación no puede ser competitiva y productiva en todo, tampoco todos los municipios ni toda una nación puede internacionalizarse y avanzar simultáneamente en la globalización, Por ello debe buscarse la vinculación al mercado mundial por medio del municipio (Molina, 1997: 933).

A pesar de que el Desarrollo Económico Regional no debe interpretarse como la solución a todos los problemas que afronta un territorio determinado, sí debe hacerse énfasis en que es una herramienta valiosa que utilizada adecua- 
damente con los apoyos técnicos y el soporte social necesario, representa una valiosa potencialidad para generar riqueza en un territorio determinado y mejorar la calidad de vida de sus habitantes (Asociación Chilena de Municipalidades, 1995:16) a través de instrumentos como: El apoyo en la promoción, fortalecimiento y desarrollo de las empresas existentes y principalmente a las de pequeña escala (micro, pequeña y mediana empresa), el mejoramiento de las condiciones regionales para promover la actividad empresarial, el fomento de la integración o diversificación de la estructura económica regional y la coordinación interinstitucional de planes, programas y proyectos de impacto regional.

Como resultado de lo anterior, es factible esperar ciertos efectos tales como: Activación de la economía local en términos de su volumen de operaciones actual y del desarrollo de sus potencialidades, aumento de ingresos y empleo, aumento de la productividad y de la calidad del empleo, aumento de la recaudación municipal y mejor calidad de vida.

Para ello es necesario elaborar estrategias concertadas entre los principales agentes del desarrollo (autoridades públicas y privadas, gremios, universidades, empresarios, trabajadores, etc.) con el fin de coordinar acciones que apunten a mejorar la calidad de vida de la población de la región.

Además, el nuevo orden económico mundial ha generado cambios sustantivos en las estrategias de desarrolio y,la descentralización se ha transformado en uno de los componentes clave de la modernización del Estado (ver Boisier, 1996:67-98), para hacer más eficiente la gestión pública, redefinir el marco de la inversión social y otorgar mayor autonomía a los municipios.

Por consiguiente, la transformación de la economía regional es producto de la interrelación entre los procesos giobales a nivel económico y social que suceden en el mundo, los procesos macroeconómicos a nivel del país y las actividades y relaciones que ocurren dentro del territorio.

\section{Municipio en el Desarrollo Local}

Las instituciones locales se encuentran hoy en día con el reto de tener que intervenir en la actividad económica, asumiendo funciones a partir de unos criterios de actuación totalmente distintos de los hasta ahora establecidos por la propia Administración Pública y defendidos por el pensamiento económico.

En múltiples foros comienza a hablarse de Desarrollo Local; "desarrollo" como proceso capaz de permitir un mejoramiento de las capacidades humanas $y$, por tanto, un alza de la producción y de la productividad de bienes y servicios favorable al crecimiento; $y$ "local" porque la localidad es el espacio donde, de manera inmediata, se concreta tal proceso; se trata de encontrar métodos para ayudar a la creación de la actividad en ámbitos locales. Los dos términos se articulan sobre el territorio.

En el rol del municipio hay que distinguir dos ámbitos estrechamente vinculados entre si. Por una parte el de sus atribuciones para incidir en el desarrollo económico local y por otra el de su función de liderazgo en la gestión de estrategias 
para generar oportunidades al conjunto de los habitantes de su territorio.

El papel del municipio en el desarrollo económico local tiene, a su vez, dos dimensiones: una con respecto al territorio y otra con respecto a las personas.

La primera se fundamenta en las competencias que tiene para crear condiciones favorables a la actividad empresarial (tanto para el fortalecimiento de las unidades económicas existentes como para la creación y atracción de nuevos negocios), en términos de uso de suelo, infraestructura vial y de comunicaciones, facilidades para el acceso a las innovaciones tecnológicas y a otros servicios que den soporte territorial a la competitividad de las empresas.

La segunda se basa en las facultades que posee para generar oportunidades en las personas, en términos de empleo y recalificación laboral, en su calidad de actor económico en la zona.

En este sentido el desarrollo debe apuntar hacia un proceso simultáneo de la sociedad y la persona, para la adquisición de conocimientos y el acceso a los recursos necesarios para disfrutar de una adecuada calidad de vida.

Al ser la Administración Local la más cercana al ciudadano, y por tanto con la que éste más se identifica, es de obligada necesidad que los municipios comiencen a dar respuesta a estas nuevas problemáticas y a implicarse en la búsqueda de soluciones para la ciudad.

Así, en el ámbito de las definiciones puede decirse que el desarrollo local es el resultado del previo compromiso de una parte significativa de la población local, mediante el que se sustituye la concepción tradicional del espacio como simple contigüidad fisica por la de un espacio de solidaridad activa y continua. Para ello es preciso que se produzcan cambios básicos en las actitudes y comportamientos de los grupos e individuos que componen la sociedad civil.

Es por ello que el desarrollo económico local puede definirse como aquel proceso reactivador de la economía y dinamizador de la sociedad local que mediante el aprovechamiento eficiente de los recursos endógenos existentes en una determinada zona es capaz de estimular su crecimiento económico, crear empleo y mejorar la calidad de vida de la comunidad local, todo ello, independientemente de las diferencias conceptuales. En la práctica el desarrollo económico local es siempre un proceso que supone la formación de nuevas instituciones, el desarrollo de nuevas empresas, la mejora de las capacidades de la mano de obra existente para hacer mejores productos y la promoción de articulaciones productivas adicionales.

Entender que el desarrollo local ha de pasar necesariamente por el desarrollo integral de un territorio, supone que las acciones que se pongan en marcha han de tener igualmente un carácter pluridimensional que relacione tanto las iniciativas del empresariado local y de las administraciones públicas como las de los demás agentes privados que intervienen en los procesos de desarrollo local. Es decir, en la formulación y ejecución de las políticas de desarrollo local cada uno de estos agentes y actores tiene un papel propio que condicionará de una $u$ otra forma el resultado final de la actuación pública.

Aunque el municipio a través de sus atribuciones no es el único factor con 
poder de impacto en la economía local, la acción municipal tiene un gran potencial para:

1. Coordinar a los diferentes agentes que intervienen en la actividad economica del territorio, para que se establezcan entre ellos relaciones de cooperación.

2. Concertar con las instituciones, los otros niveles territoriales y el sector privado, un plan de desarrollo económico local. La administración del territorio es la más adecuada para conseguir una integración de las diferentes politicas sectoriales que llevan a cabo las instituciones públicas y que afec$\tan$ al territorio

3. Dotar a su territorio de espacios adecuados para la localización de empresas, en función de las necesidades de la economía moderna. Las empresas ya no buscan sólo grandes espacios disponibles, mano de obra barata o tributos excepcionales. Buscan, sobre todo, un conjunto de servicios complementarios que generen condiciones favorables para hacer negocios, no sólo para producir.

En este orden de ideas, la decisión y voluntad de apoyo de alcaldes y concejales resulta fundamental para impulsar desde el municipio, el desarrollo económico local en toda su extensión.

De igual manera es crucial establecer una coordinación entre las diversas direcciones y departamentos al interior de la administración municipal, dado que las distintas unidades municipales tienen funciones que afectan directamente la actividad económica.

En consecuencia, un proceso de esta naturaleza y magnitud articuladora no es concebible sin el respaldo institucional de la Alcaldía como la máxima autoridad política del municipio.

\section{Las políticas locales de desarrollo productivo}

\subsection{Qué son las políticas?}

La eficiencia con que se utilizan los recursos productivos $y$, consecuentemente, la productividad de la economía dependen tanto de las habilidades y capacidades de cada una de las empresas como de factores externos a ellas, los cuales constituyen el entomo en que se desarrollan.

Se han hecho numerosos intentos para sistematizar estos factores externos que influyen en el nivel de competitividad de las empresas. Porter (1991) identifica cuatro atributos genéricos de una nación que conforman el entorno en que han de competir la empresas locales y que fomenta o entorpece la creación de ventajas competitivas: 1) Condiciones de los factores (calificación general y específica de la mano de obra, recursos físicos, infraestructura científica, recursos de capital, infraestructura física); 2) Condiciones de la demanda interna (composición, grado de exigencia, intemacionalización de la demanda, etc.); 3) Sectores conexos y auxiliares (presencia de encadenamientos productivos y externalidades entre sectores conexos) y 4) Estrategia, estructura y rivalidad de la empresa (grado de rivalidad local, vinculaciones entre las empresas productivas y las instituciones financieras, etc.).

Estos factores actúan a su vez sistemáticamente, lo que conduce a que 
Política municipal para el desarrollo de la Micro, Pequeña y Mediana Empresa Tarapuez Chamorro, Edwin

surjan importantes problemas relacionados con la presencia de externalidades y de fallas de coordinación que los convierten en áreas objetivo de la política gubernamental, fundamentalmente por medio de instrumentos horizontales.

En este sentido, las políticas especiales dirigidas a las MIPYMES, encuentran un lugar fundamental debido a que estas unidades enfrentan fallas de mercado mucho mayores que las de las grandes empresas.

En efecto, las políticas municipales, instrumentadas mediante diversos mecanismos, que pueden ir desde los tradicionales de corte fiscal o financiero hasta otros más específicamente encaminados a promover la capacidad laboral o la investigación científica y tecnológica de las MIPYMES, tienen efectos importantes en la creación y oferta de los factores productivos, su cantidad y calidad, tanto a nivel local y regional como nacional.

En este orden de ideas, una política local para el desarrollo, competitividad, promoción y fortalecimiento de las MIPYMES es, por tanto, una síntesis mediante la cual las lógicas de mercado y de autoridad municipal se complementan. En la práctica pueden adoptar una gran variedad de modalidades a partir de la amplitud de la intervención estatal y de los márgenes dejados a la acción de las fuerzas del mercado. Aunque parezca extraño, la globalización ha aumentado la importancia de la vida local. Desde hace tiempo, los científicos políticos saben que toda política es local. $Y$ ahora este principio se está haciendo evidente también en el mundo de los negocios.
En todo caso, una definición mínima de política local para el fortalecimiento empresarial es aquélla que la concibe como la organización de los esfuerzos y de las acciones de los agentes sociales para el logro de un objetivo amplio y genérico: el desarrollo, competitividad, promoción y fortalecimiento de las MIPYMES del municipio.

El problema, sin embargo, radica en que la mera existencia de objetivos y la sumatoria de medidas no constituyen per se una politica. Lo que sobre todo se requiere es plantear un conjunto unitario de medidas integradas en un programa político que al tiempo que eluda los peligros de contradicción o neutralización característicos de un proceso desarticulado de formulación de medidas, optimice su potencial retroalimentador (Gonzalez, 1998: 532), sin perder de vista que la acción del gobiemo municipal, en todo caso, debe ser parcial.

Establecidas estas bases, la política no puede empecinarse en darvida artificial a aquéllas actividades en las que el municipio no tiene argumentos competitivos. Sin embargo debe incorporarse un criterio excepcional para apoyar aquéllas actividades (inexistentes en el municipio o con problemas) mediante las cuales puedan soportarse otros objetivos como el aumento del empleo, la generación de ingresos y el incremento del valor agregado regional o actividades que de una $u$ otra manera apoyen clústers o cadenas productivas regionales. Se trata, por tanto, de una política que reconoce la necesidad de excepciones.

Las políticas de desarrollo empresarial local deben buscar, entre otros, los siguientes objetivos: 
- Ser gestionadas integralmente con el objetivo común de orientar la producción hacia sectores de mayor valor agregado e imprimir mayor eficacia a la inserción nacional e internacional de la economia regional.

- Condicionar las políticas de incentivos a criterios de reciprocidad, por lo que el sector privado se compromete a cumplir ciertas metas referentes a la cantidad producida, precios de venta, contenido regional y nacional, inversión en tecnología y capacitación del recurso humano, entre otros.

- La coherencia y eficacia de las politicas de desarrollo se sustentan fundamentalmente en la estabilidad y relativa autonomía de una burocracia desarrollista bien consolidada. Ese marco institucional ha permitido mantener la corrupción y la búsqueda de rentas improductivas en niveles compatibles con el éxito de las políticas.

\subsection{Medidas de una política de desarrollo productivo}

A grandes rasgos, las medidas de una política productiva pueden clasificarse en:

- Sustantivas: son las que están directa y expresamente dirigidas a propiciar mayores niveles de productividad. Actúan sobre el proceso productivo, es decir, sobre las condiciones endógenas en que éste se lleva a cabo. Por ejemplo, el desarroilo de las MIPYMES en la promoción de la investigación, la formación del talento humano y la reconversión ambiental, entre otras medidas.
- Contextuales y de fomento: son las que apoyan y complementan a las sustantivas. Influyen en los condicionantes exógenos del acto productivo. Entre las medidas contextuales podría mencionarse la ampliación y mejora de la infraestructura, la gestión ambiental, la normalización con base en criterios internacionalmente aceptados y la promoción de la asociación interempresarial, entre otras. En cuanto a las medidas de fomento pueden citarse los estimulos fiscales y los estímulos financieros de corte preferencial, por mencionar algunas.

Elementos de una política de desarrollo productivo

Los elementos (Gonzalez, 1998: 534-536) más importantes de una política productiva son: La definición de objetivos con metas especificas susceptibles de evaluación, la determinación de prioridades sectoriales en el municipio, la sincronización del desarrollo del sector productivo con el de otros sectores como el financiero y el académico y la necesaria coordinación de la política productiva con otras políticas como la educativa y la ambiental.

Finalmente, para la formulación e instrumentación de la política municipal de desarrollo de las MIPYMES se requiere de una estrategia de comunicación para informar, retroalimentar y crear consenso. Ello significa ir más allá de la sola difusión de las bondades de dicha politica. Ante todo, la estrategia de comunicación deberá buscar la apertura de canales eficaces de información y particularmente estrategias de interlocución y diálogo permanentes, como base fundamental de un acto de concertación con los actores municipales. 
Politica municipal para el desarrollo de la Micro. Pequeña y Mediana Empresa

Tarapuez Chamorro, Edwin

\subsection{Política municipal para el desarrollo de las MIPYMES}

Una política municipal para el desarrollo de las MIPYMES busca generar un apoyo integral a las empresas de pequeña escala, de tal forma que so eviten los esfuerzos aislados de los diferentes agentes del municipio y sobre las distintas variables que influyen en el desarrollo empresarial.

En este mismo sentido busca desarrollar el potencial de las personas y grupos sociales del municipio en la medida en que el gobiemo local debe facilitar los mecanismos para acercarce a uno de los anhelos más arraigados en las personas cual es el de ser dueños de su propia empresa.

El tema de la creación de empresas se convirtió en política nacional con la aprobación de la Ley 590 de 2000 , más conocida como Ley MIPYME. Por ello, y con el fin de apoyar la política nacional, es necesario que a nivel municipal se genere y adopte una política local para el desarrollo de la micro, pequeña y mediana empresa, que apoye en el ámbito regional la aplicación de los instrumentos de carácter nacional y que a la vez promueva la aplicación y diseño de otros instrumentos que a nivel territorial son de su competencia.

En muchas ocasiones se ha afirmado en que en el municipio de Pasto (y en general en el departamento de Nariño) no existe cultura empresarial. Ello es totalmente falso pues el municipio sí posee una cultura empresarial sino que esta es diferente a la de las demás regiones del país. En últimas, la disposición de los pastusos para crear empresas constan- temente a pesar de las condiciones adversas del medio circundante y el gran espíritu trabajador del empresario local, son algunas pruebas fehacientes de nuestra cultura empresarial, una cultura que se impone a pesar de las limitaciones y la falta de estímulos estatales.

A pesar de ello nuestra cultura empresarial también se caracteriza por la escasa planeación, una marcada visión cortoplacista, la escasa disposición para la capacitación y actualización, la falta de unión de esfuerzos para constituir empresas de mayor proyección y la escasa integración con los mercados nacionales e internacionales son, entre otras, algunas características que paulatinamente deben ir modificándose para generar una nueva cultura empresarial, más dinámica y con mayores alcances.

De otra parte, ante el cambio de modelo económico, la crisis de la economía colombiana (y por ende de las regionales) y los consecuentes recortes de personal de las empresas públicas y privadas, se hace necesario diseñaruna política municipal que promueva el desarrollo de las MIPYMES como un mecanismo ideal para la generación de empleo, redistribución de la ríqueza, generación de mayor valor agregado y mayores recursos para inversión pública por la vía impositiva. Este mecanismo se viene implementando a nivel mundial como consecuencia de una tendencia global. Debido a ello, el mundo está pasando de una sociedad de empleados a una sociedad de empresarios en pequeña escala.

De igual manera, así como el Estado pretende estimular al sector privado para generar más y mejores empresas, debe paralelamente crear los instrumen- 
tos necesarios para que este proceso sea mejor y más expedito, que minimice los obstáculas institucionales que dificultan la creación y desarrollo de las empresas y que a la vez les brinde un apoyo integral.

\subsection{Principios que Orientan la Política Municipal para el Desarrollo de las MIPYMES}

Integralidad: Tradicionalmente los instrumentos de apoyo al sector de las MIPYMES han estado enfocados a brindar soporte en los diferentes campos del desarrollo empresarial. De esta manera, se han establecido programas de capacitación, mercadeo y comercialización, exenciones tributarias y asistencia técni$\mathrm{ca}$, entre otros.

Estos programas han adolecido de la integralidad necesaria que le permita a las empresas aprovechar cabalmente los diferentes programas y estrategias de apoyo.

Se pretende evitar la implementación de programas aislados que conlleven a resultados parciales que no desarrollen la empresa como un todo.

Cooperación: Se ha sostenido repetidamente que en el municipio de Pasto a la gente no le gusta unirse para crear empresa. Pero este factor se presenta no solamente en nuestro departamento y en sus municipios sino en todas las regiones del país y en todos los países del mundo. La individualidad, la desconfianza y el anhelo de poseer aigo propio, son caracteristicas propias de la naturaleza humana que se desarrollan más en unas culturas que en otras dependiendo de ciertos factores que pueden alentarlas a crecery desarrollarse.
De igual forma algunas de nuestras instituciones han creado ciertos afanes de protagonismo, to cual se ha convertido en un obstáculo para brindar opciones integrales de apoyo al sector de las MIPYMES.

La cooperación, entonces, se convierte en un factor fundamental en la implementación de una política de desarroIlo para las MIPYMES.

Flexibilidad: Los distintos grados de desarrollo de las empresas, un entomo socioeconómico relativamente cambiante, al igual que las diferentes posibilidades, capacidades, habilidades y destrezas de los futuros empresarios, demandan flexibilidad en los programas $y$ estrategias que se adopten dentro de una política municipal para el desarrollo de las MIPYMES.

Universalidad: Una política municipal para el desarrollo empresarial se enfrenta a una variada gama de empresas en los diferentes sectores económicos, con distintos tamaños y diferente clasificación. Se entrenta, igualmente, a diferentes concepciones religiosas, politicas e ideológicas por parte de los empresarios o candidatos a serio.

Por ello, una política municipal para el desarrollo empresarial no debe discriminar el tamaño ni el sector económico de las empresas, ni la condición social, religiosa, sexual o politica de su (s) propietario (s), ni su procedencia regional.

\subsection{Principales componentes de una Política Municipal para el Desarrollo de las MIPYMES}

Política Ambiental: Cada vez con mayor fuerza, la sociedad presiona al Estado para que adopte medidas orientadas 
a regular aquellas actividades del hombre que deterioran su medio ambiente.

En todos los municipios de Colombia, desde los más pequeños hasta los más grandes, la calidad de vida de la comunidad depende sustancialmente de la base natural de que disponga el municipio.

En un contexto global como el que se vive en la actualidad, es fundamental que se garantice un desarrollo empresarial que promueva la utilización de tecnologías no contaminantes de tal forma que se asegure la sostenibilidad del medio ambiente.

En el proceso de formulación de las políticas ambientales del Municipio debe darse una interacción directa entre el gobierno local y las empresas ubicadas en su jurisdicción.

Tradicionalmente los instrumentos de gestión ambiental se han clasificado en la literatura entre la intervención directa y el control y los incentivos económicos. Con relación a los primeros se requiere de un aparato institucional de vigilancia del cumplimiento importante, y generan pocos incentivos para el cambio tecnológico y cultural hacia prácticas de producción y consumo más "limpias" o sostenibles. Los incentivos, por su diseño más flexible a la racionalidad de los agentes económicos, pueden requerir menos costos de implementación o vigilancia, pero en algunos casos información técnica más costosa para su diseño.

Como acciones generales en la política ambiental: Se pueden consederar las siguientes:

- Determina algunas exenciones tributarias a las empresas que se reubiquen en zonas de menor impacto am- biental, que reemplacen su maquinaria y equipos por otros menos contaminantes, que reduzcan su impacto ambiental negativo y que utilicen materiales de reciclaje dentro de su proceso de transformación, entre otros.

- Gran parte de los empresarios miran las restricciones y normas ambientales como una gran amenaza que eleva los costos de producción u peración de sus empresas. Por ello es necesario realizar campañas de concientización sobre el medio ambiente.

- Es necesario replantear la necesidad de la actualización de maquinaria y equipo contaminante por otras tecnologias que generen un menor impacto ambiental negativo.

- La labor de la Secretaría Municipal del Medio Ambiente y de Corponariño debe ser un trabajo de acompañamiento al empresario y no simplemente de un control punitivo sobre las fallas estructurales de la economía local que se reflejan en las MIPYMES.

- La reubicación de algunas empresas, tales como las del subsector de curtiembres ubicadas en Pandiaco $y$ Juan XIII, debe estar acompañada de medidas alternativas para evitar el desplazamiento per se de dichas empresas. A pesar del impacto negativo que están generando, el gobierno municipal debe proponer soluciones alternativas que generen un consenso alrededor de temas tan importantes para el desarrollo socioeconómico del Municipio.

- La creación de un Parque Industrial es un proyecto prioritario, no solamente para reducir el impacto ambiental de las industrias locales sino 
para generar economlas de escala en la región. La Ley MIPYME en su articulo 30 dice que el Gobierno Nacional propugnará el establecimiento de parques industriales, tecnológicos...

- Las entidades competentes deben permitir que las empresas del mismo subsector puedan realizar estudios de impacto ambiental de manera asociada ya que gran parte de las causas y efectos tiene un mismo origen.

- En general los empresarios piensan que la contaminación solamente se da por vertimiento de residuos a las fuentes de agua y de gases a la atmósfera. Ello requiere el desarrollo de un programa de capacitación al sector productivo para dar a conocer la gran variedad de formas de contaminación ambiental.

\subsection{Política de capacitación del talento humano}

Podría afirmarse que una auténtica democracia implica necesariamente una política de desarrollo del talento humano, es decir, que en la medida que las, regiones, los municipios y el país en general cuenten con oportunidades de capacitación a todo nivel y de acuerdo a los requerimientos del sector productivo, se generará una distribución más equitativa de oportunidades laborales, económicas y sociales para los habitantes de la región.

En cuanto al desarrollo empresarial, los problemas del talento humano guardan una estrecha relación con los siguientes factores: Los vinculados con el subdesarrollo de habilidades, el conocimiento y el talento de las personas y los que surgen de la subutilización de las energías y capacidades de las personas (Pinto/Suarez, 1999: 115).

Ante todo se hace necesario estructurar una política municipal orientada a potenciar la capacidad empresarial y de gestión, así como el recurso humano de las MIPYMES.

De otra parte en Pasto se habla del divorcio entre la universidad y el sector productivo. En realidad sí existe una relación aunque no está dada de manera formal ni continua. Ello se puede observar en los siguientes aspectos:

- Son las instituciones de educación superior (IES) las que proveen, en su mayor parte, el recurso humano calificado que emplean las empresas locales.

- Las pasantias y prácticas de los estudiantes en las diferentes empresas de la región. Esta estrategia permite que los estudiantes conozcan más de cerca las empresas, desarrollen mayor capacidad para la transferencia teórico-práctica, tengan mayor flexibilidad frente a las estructuras empresariales y permite que las empresas realicen recomendaciones ante las universidades, entre otros beneficios.

- Gran parte de los directores gremiales se encuentran vinculados con la academia en calidad de docentes en las diversas instituciones de educación superior

- La vinculación periódica de empresarios en calidad de conferencistas en los diversos programas académicos

- Algunas investigaciones sobre empresarios regionales y los factores que influyen en su desempeño

- Realización conjunta de eventos de promoción comercial como la Sema- 
Politica municipal para el desarrollo de la Micro, Pequeña y Mediana Empresa Tarapuez Chamorro, Edwin

na de la Empresa, realizada entre ACOPI (Asociación Colombiana de Pequeños Industriales) y CESMAG (Centro de Estudios Superiores María Gorelti) y otros muestras comerciales y empresariales realizadas por estudiantes en otras instituciones como la Universidad Cooperativa y la Universidad de Nariño.

- Los programas de capacitación labo. ral para jóvenes desempleados ade. lantados por la Red de Solidaridad Social en convenio con la Universidad Autónoma de Nariño y el CES. MAG, entre otros.

A pesar de ello debe recalcarse que faltan canales de comunicación que retroalimenten a ambas partes sobre las necesidades de capacitación de las empresas y la calidad de la educación y formación que se imparte en las aulas universitarias.

Al respecto cabe anotar que entidades como CESMAG (Centro de Estudios Superiores María Gorelti) han realizado estudios sobre demanda de programas académicos a los futuros estudiantes y algunos sondeos entre los empresarios sobre las necesidades de formación profesional y tecnológica y los resultados confirman la elevada demanda hacia programas relacionados con Sistemas, Administración, Medicina, Psicología y Derecho, entre otros. Actualmente el CESMAG (Centro de Estudios Superiores Maria Gorelti) se encuentra rediseñando los planes de estudio en todos sus programas académicos con el fin de formar personas con mentalidad emprendedora que sean capaces de formar sus propia empresa.
Lo anterior no significa que dicha relación no deba fortalecerse y estructurarse mucho más. De hecho muchas universidades viven pendientes solamente de superar a sus competidores independientemente de la calidad que ofrecen y de su relación con el sector empresarial. A la vez, muchos empresarios viven encerrados en su diario quehacer de alcances cortoplacistas.

En cuanto al desarrollo tecnológico (a pesar de que no se propone una politica exclusiva para esta variable), es conveniente una acción pública de promoción de empresas, organizaciones y redes universitario-tecnológicas-empresariales en las que se acumule y circule el conocimiento sobre las formas organizativas y tecnológicas que permitan un aumento de la productividad no basado exclusivamente en el aumento de capital fijo. En cuanto a su financiamiento, la participación pública debe ser parcial, no tanto por la cuantía de los financiamientos ya que las experiencias muestran que se requieren montos relativamente modestos de recursos, sino como un medio para incentivar la participación de los propios interesados.

Entre las Acciones generales en la política de talento humano tenemos:

- Estimular a los empresarios a adquirir servicios de capacitación y asesoría para prepararse con mayor proyección en el nuevo entorno de la economía global.

- Creación de programas de educación formal y no formal enfocados a la capacitación gerencial y oferta de cursos y seminarios a nivel de todas las facultades de las universidades $y$ centros de educación superior. 
- Inclusión de la metodología de educación empresarial en las instituciones de educación superior locales y en los colegios del municipio, para la promoción de empresarios líderes y el desarrollo del espíritu empresarial. Debe revisarse los pénsum académicos de todas las carreras y no solamente las del perfil empresarial.

- Mayor vinculación de los directivos universitarios con el medio externo.

- Creación y desarrollo de muestras empresariales con los proyectos productivos más innovadores que creen los estudiantes de colegio y universitarios.

- Mejoramiento de los programas de capacitación y asistencia técnica que brinda el Servicio Nacional de Aprendizaje (SENA) en la regional de Nariño, especialmente en el municipio de Pasto.

- Desarrollo de programas conjuntos y complementarios de capacitación y asistencia técnica en las empresas.

- Generar programas básicos de cualificación que vinculen a los empresarios con los computadores y el internet, ya que estas son dos herramientas muy valiosas para el desarrollo de las MIPYMES que aún no se han establecido en muchas empresas.

- Generar beneficios tributarios a las empresas que capaciten a sus trabajadores o vinculen laboralmente a personas de los sectores más vulnerables de la población (minusválidos, jóvenes, mujeres, entre otros)

- Desarrollo de programas para la formación de asesores y consultores especializados en temas de MIPYME.
- Gestión de programas de cooperación internacional para la vinculación de expertos jubilados de otros países, con amplia experiencia en asesoría y consultoría en empresas MIPYMES.

- Articulación de esfuerzos con las diferentes instituciones públicas y privadas que realizan cualificación empresarial. En muchos casos las entidades realizan los mismos programas, con lo cual se desperdician recursos que podrían invertirse en otros programas. Seria conveniente especializar la capacitación por entidades o sectores económicos y que se genere un plan anual de cualificación empresarial para que se eviten repetir algunos programas.

\subsection{Política de Comercialización}

Los problemas de comercialización que afectan a las MIPYMES se enfocan básicamente a la tendencia local del mercado de las empresas ubicadas en el Municipio de Pasto y a la falta de información de mercado para una adecuada toma de decisiones estratégicas.

Aunque la mayor parte de las MIPYMES orientan sus ventas hacia el mercado doméstico, se considera indispensable iniciar una política cuyo objetivo sea el de modificar la visión de los negocios. En este sentido es necesario que el gobierno municipal y las demás entidades encargadas de la promoción empresarial, promuevan la mentalización del empresariado en torno a que debe emplearse una gran variedad de estrategias que motiven el consumo de los productos locales y se evite la conquista del merca- 
do local por parte de productos importados de otros departamentos o países.

Posibles acciones generales en la política de comercialización serian:

- Generar una red de proveedores del Gobierno Municipal que se encargue de ofrecer los bienes y servicios que demanda la Alcaldia.

- Generación de espacios periódicos de promoción comercial (preferiblemente especializados), tales como muestras comerciales, ruedas de negocios y ferias especializadas.

- Capacitación en comercialización, atención al cliente, participación en eventos comerciales, estrategias de mercadeo y comercio internacional, entre otros temas.

- Adopción, por parte del gobierno municipal y de todos sus establecimientos, de un estatuto de contratación que promueva la vinculación de las empresas y recursos locales. Dicho estatuto debe estar en concordancia con la Ley 80 de 1993. Un ejemplo valioso es el Estatuto de Contratación para las Empresas de Servicios Públicos Domiciliarios de Cali.

- Generar paulatinamente procesos de producción ambientalmente sostenibles para exportación de "productos ecológicos".

- Vincular a las universidades en la sensibilización y capacitación de los empresarios para la utilización de internet como herramienta para promover el comercio electrónico.

- Vincular a los estudiantes de los últimos semestres de ingenieria y tecnología en sistemas de las universidades regionales en la asesoria para el diseño de las páginas web de las empresas locales.

- Determinar algunas exenciones tributarias para la empresas que sobrepasen cierto límite de ventas anuales.

- Vincular al Laboratorio Colombiano de Diseño en programas de mayor cobertura hacia el sector de las MIPYMES, que contribuyan al mejoramiento de los productos locales ya que sus acciones se han especializado en el sector artesanal de la región.

- Gestionar los recursos necesarios para lograr los certificados de calidad necesarios para poder competir en mercados internacionales con productos manufactorados (ISO 9000, ISO 14000 y Sello Ecológico, entre otros).

\subsection{Política de Financiamiento}

Tradicionalmente el sector financiero ha desempeñado un papel determinante en la promoción del desarrollo económico. Con la globalización, la apertura económica y el crecimiento de la competencia, este sector se ha convertido en clave para aumentar la inversión y la productividad y las condiciones necesarias de inserción en los mercados internacionales.

Se ha demostrado que mientras más se encuentre desarrollado el sistema financiero de un país mejor se distribuyen sus recursos, mayores son los niveles de ahorro, más acelerada es la tasa de formación de capital doméstico y superiores son los beneficios para las actividades productivas.

Esta es una de las variables en la que más énfasis hace el empresario ya que normalmente el las MIPYMES no dis- 
ponen de efectivo para capital de trabajo, para adquisición de maquinaria o para ampliación de su producción. Por ello es de tanto interés para los empresarios del sector.

Como acciones generales en la política de financiamiento se proponen:

- Creación de una entidad de crédito para el municipio de Pasto.

- A nivel municipal entidades como la Fundación Promover de la Cámara de Comercio de Pasto, Caja de Compensación Familiar de Nariño, Fondo Regional de Garantías y Contactar, disponen de recursos o estrategias de soporte de crédito para creación de empresas. Estas entidades podrian unirse para otorgar planes conjuntos de financiación al sector de las MIPYMES municipales.

- La Alcaldía Municipal, conjuntamente con otras instituciones privadas y los empresarios podrian constituir un Fondo Regional de Capital de Riesgo encargado de financiar aquéllos proyectos de empresa viables financiera y estratégicamente de acuerdo con los estudios pertinentes (como el Estudio de Competitividad para el Departamento de Nariño y el de los clusters regionales). Temporalmente el Fondo sería socio de las empresas que se apoye. El artículo 24 de la Ley 590 de 2000 crea el Fondo de Inversiones de Capital de Riesgo de las micro, pequeñas y medianas empresas rurales (EMPRENDER), cuyo objeto es apoyar a los empresarios MIPYMES asentados en áreas de economía campesina, estimulando la creación y fortalecimiento de empresas rurales, mediante el aporte de ca- pital social y el financiamiento de la preinversión, en asocio con los productores y las entidades territoriales.

- Las Instituciones de Educación Superior podrian dedicar un $1 \%$ de su presupuesto anual para incentivar la creación de empresas entre sus estudiantes, a través del crédito que realizarian los centros educativos.

- Exenciones tributarias a las entidades financieras que intermedien recursos de crédito del IFI, Bancoldex y Finagro hacia las MIPYMES locales.

\subsection{Política de impuestos municipales}

La variable impuestos es tal vez una de las más difíciles de controlar por parte del gobierno con respecto al recaudo que se genera de acuerdo con la actividad productiva de una determinada zona.

En últimas, cuando se tiene que exigir el pago de impuestos de una manera general y compulsiva, se observa una gran debilidad de la Alcaldia para satisfacer las necesidades de los contribuyentes del Municipio. Es fundamental, dentro de la gestión municipal, que la Alcaldía recompense con creces los impuestos que pagan sus contribuyentes, ya que a nadie le gusta participar en una relación donde una de las partes cumple con su obligación sin recibir la contraprestación por lo que está cancelando.

A través de una política fiscal municipal se podrian articular gran parte de los elementos de las demás políticas, con exenciones por los siguientes conceptos:

- Establecimiento de nuevas empresas dentro del territorio municipal. 
Política municipal para el desarrollo de la Micro, Pequeña y Mediana Empresa Tarapuez Chamorro, Edwin

- Generación de puestos de trabajo adicionales.

- Reubicación de empresas en determinadas zonas del municipio.

- Ampliación productiva.

- Reconversión industrial, desarrollo tecnológico o actualización de maquinaria y equipos.

- Utilización de materiales de reciclaje en el proceso productivo o participación en campañas ambientales.

- Formalización de vendedores ambulantes y estacionarios.

- Capacitación del personal de la empresa.

- Vinculación de personas discapacitadas en calidad de empleados o de los grupos de personas que presentan los mayores niveles de desempleo (jóvenes, mujeres, profesionales de determinada edad, etc.).

- Donaciones a entidades culturales, deportivas y cívicas, entre otras.

- Uso intensivo de mano de obra.

- Sobrepasan cierto límite de ventas anuales o exportaciones.

- Asociaciones entre empresas.

- Intermediación de recursos de crédito para MIPYMES.

A pesar de lo anotado inicialmente en este aparte, la variable impuestos puede constituirse en un mecanismo favorable para la ampliación, creación, fortalecimiento y desarrollo de las MIPYMES del municipio.

\section{Ente articulador de la política}

La implementación de una política municipal para el desarrollo de las
MIPYMES requiere que los empresarios tengan un interlocutor directo en el gobierno municipal, es decir que debe existir un encargado con el cual éstos se relacionen. Para llevar a cabo este propósito, se pueden dar dos modalidades:

1. A través de la redefinición de funciones de alguna dependencia municipal, o

2. Creación de una Secretaría u oficina municipal para tal propósito

La implementación de cualquier alternativa dependerá de las condiciones de cada municipio. El desarrollo que alcance el programa no dependerá tanto de su ubicación dentro de la estructura municipal, sino principalmente de la inversión que se realice en talento humano especializado, equipamiento, infraestructura y gastos de funcionamiento: (Asociación Chilena de Municipalidades, 1995: 93-94).

Para el caso del Municipio de Pasto y con el fin de darle la importancia necesaria, gran parte de los empresarios consultados coinciden en sugerir la creación de la Secretaría de Fomento y Competitividad Empresarial, que debe ser una dependencia ágil y enfocada al trabajo directo con el sector privado, con una planta de personal muy reducida (6 personas) con el fin de no generar mayor burocracia en la administración municipal.

La función básica del personal de la Secretaria es la de generar un proceso de integración entre las diferentes entidades públicas y privadas de apoyo a las MIPYMES, tanto en el ámbito municipal, nacional e internacional. De esta manera el personal de la Secretaría asesoraría a los empresarios sobre las entidades que pueden colaborar o apoyar su desempe- 
ño en los diferentes campos de capacitación, asesoría, comercialización, registros e impuestos, entre otros temas. La Secretaria no prestaria directamente ningún servicio de apoyo a los empresarios, excepto el de información y orientación.

Mientras más calificado sea el equipo de trabajo de la Secretaria, mejores serán las perspectivas en térmínos de cobertura e impacto de la dependencia. Otro elemento fundamental es el establecimiento de coordinadores a nivel municipal, lo cual puede realizarse conjuntamente con los gremios, asociaciones de empresarios, ONGs y entidades públicas con presencia en el Municipio y que estén relacionadas con el desarrollo empresarial.

Para tener una adecuada relación o enlace con el sector empresarial del municipio se requiere: Poseer conocimientos básicos en las temáticas vinculadas a la actividad empresarial: entorno económico regional, nacional e internacional, mercadeo y comercialización, finanzas, constitución de empresas, impuestos y trámites, entre otros; conocer los instrumentos e instituciones de apoyo disponibles a nivel municipal, departamental y nacional; tener un conocimiento global de lo que sucede en el Municipio y el pais en general con el fin de ser propositivos en los aspectos relacionados con el sector empresarial.

La Secretaria de Fomento y Competitividad Empresarial tendrá como misión liderar la politica local para el desarrollo, competitividad, promoción y fortalecimiento de las micro, pequeñas y medianas empresas (MIPYMES) en el municipio de Pasto, facilitando las relaciones entre el gobierno y el sector privado como un mecanismo fundamental para generar una dinámica que permita acelerar el desarrollo del sector productivo y a través de él garantizar un mejor nivel de vida a sus habitantes. La secretaria tendría como responsabilidades generales los siguientes:

- Participar activamente en la definición de las políticas municipales para el desarrollo, competitividad, promoción y fortalecimiento de las MIPYMES y sus implicaciones sectoriales.

- Coordinar, con las entidades públicas y privadas involucradas con el sector de las MIPYMES, la ejecución de las políticas, programas, proyectos y demás orientaciones determinadas en el Plan de Desarrollo Municipal para facilitar, estimular y sostener el desarrollo de la base productiva local.

- Promover conjuntamente con otras instancias gubernamentales y privadas, estrategias y programas de comercialización a nivel regional, nacional e internacional de los productos de las empresas MIPYME del municipio y a la vez promover que la demanda de bienes y servicios realizada por parte del gobierno local y los consumidores municipales, se realice primordialmente con empresas ubicadas en el municipio de Pasto.

- Identificar, formular y gestionar los proyectos de inversión requeridos para promover el fomento económico y la competitividad de la economía local.

- Promover, conjuntamente con el sector financiero y otras entidades relacionadas, la canalización de fondos, la flexibilización de crédito y sus procedimientos y la creación de mecanismos de apoyo financiero al sector de las MIPYMES. 
Politica municipal para el desarrollo de la Micro, Pequeña y Mediana Empresa Tarapuez Chamorro, Edwin

- Identificar, promover, coordinar y apoyar planes y programas de desarrollo tecnológico, formación del recurso humano y promoción del espíritu empresarial.

- Promover la asociación para facilitar y concertar con el sector privado, las instituciones educativas, organizaciones no gubernamentales y gremios de la producción, los programas y proyectos necesarios para el desarrollo de los sectores comercial, agropecuario, de servicios, industrial y turístico y proponer los programas de articulación interinstitucional y de cooperación internacional pertinentes.

- Las demás que le sean necesarias para el cumplimiento eficiente y eficaz de su misión, de acuerdo con la Constitución Nacional, las Leyes y los Acuerdos Municipales.

\section{Servicios para el sector empresarial}

Como se ha mencionado, el propósito no es que el personal de la Secretaria preste los servicios directamente al empresariado, sino que ejerza un liderazgo que permita conseguir todos los servicios necesarios a través de alianzas estratégicas con las entidades públicas y privadas que tienen relación con el sector empresarial.

Una situación generalizada es que se ha venido realizando un trabajo aislado, tanto a nivel de instituciones individuales como en los diferentes componentes y variables que influyen en el desarrollo empresarial. Algunas instituciones han hecho énfasis en capacitación, otras en comercialización y otras en financiamiento, pero no se ha logrado encadenar estos esfuer- zos para brindar un apoyo integral a las empresas del municipio.

A nivel general la Secretaría podría ofrecer los siguientes servicios:

1. Orientación e información. Habitualmente los empresarios y potenciales empresarios que se acercan al Municipio, al menos en gran parte, van en busca de información y orientación. Para satisfacer esta demanda la información que debe estar disponible en la Secretaría se cataloga en dos grupos:

- Información interna: demografía, mercado laboral, vivienda, actividad económica, transporte, infraestructura vial, servicios públicos, telecomunicaciones, requisitos para pago de impuestos municipales y datos medioambientales, entre otros.

- Información externa: información financiera y crediticia, mercados para compra y venta de bienes y servicios, tecnología, capacitación, requisitos para constituir empresas, trámite para pago de impuestos nacionales, cooperación internacional, ministerios y entidades de apoyo al desarrollo de las MIPYMES, entre otros.

2. Formalización. La informalidad de las empresas representa una dificultad o impedimento para el desarrollo económico de un municipio ya que genera un empleo de bajas calidades $y$ afecta negativamente el recaudo de impuestos, con las consecuencias nefastas sobre la inversión social. Formalizar a los "empresarios informales" no es una tarea fácil ya que en principio el Municipio no dispone de soluciones de corto plazo para solucionar el problema del desempleo y, a 
la vez, gran parte de dichas personas llevan muchos años ejerciendo su labor de manera informal.

3. Reducción de trámites para constitución o renovación de empresas. La Alcaldía podría generar un proceso para reducir los numerosos trámites que una persona debe llevar a cabo para constituir una empresa o renovar su matrícula mercantil.

\section{Consideraciones Finales}

A tono con las nuevas orientaciones internacionales, el desarrollo local y regional viene cobrando cada vez una mayor importancia como consecuencia de la falta de resultados positivos de los diferentes modelos de desarrollo centralizado que habian venido imponiéndose en todo el mundo.

En este sentido, ante el cambio de modelo económico, el Municipio se erige como la célula más importante del territorio nacional, no en cuanto a extensión sino en lo referente a todos los procesos socioeconómicos y culturales que en el interior de cada localidad se llevan a cabo.

Ello ha implicado que los modelos de desarrollo empresarial hayan tomado como base las micro, pequeñas y medianas empresas, y no las grandes firmas manufactureras o empresas multinacionales, ya que la flexibilidad y elevada capacidad de adaptación que permiten las primeras es un factor difícil de lograr en las segundas.

Hablar de una política municipal de desarrollo productivo implica tener muy presente el concepto de integralidad, es decir, que no pueden realizarse esfuerzos aislados. Ello a la vez conlleva a que las instituciones públicas y privadas de apoyo al sector empresarial, bajo la coordinación de la Alcaldía Municipal, aporten con sus recursos, programas, logística y gestión, en la atención al empresario en todos las variables que influyen en el desarrollo empresarial. En últimas, unas entidades promoverán la capacitación, otras la comercialización, otras formularán mecanismos de apoyo tributario, otras promoverán mecanismos para garantizar un mayor acceso a los recursos del crédito, entre otros aspectos.

En el contexto nacional existe una gran variedad de instrumentos, programas, estrategias e incentivos que deben gestionarse para el desarrollo de las empresas locales. En este contexto, las entidades consultadas, y entre ellas principalmente los gremios de la producción y asociaciones de empresarios del municipio de Pasto, han captado recursos valiosos para programas de capacitación y comercialización, principalmente. Desafortunadamente los programas para la promoción del comercio exterior, aseguramiento de la calidad, desarrollo tecnológico, incentivos tributarios y financiamiento, principalmente, no han tenido un mayor impacto sobre el sector empresarial local. Ello se debe, en gran parte a la falta de interés por parte de los empresarios y a un escaso poder de gestión y motivación por parte de las entidades locales.

La coordinación interinstitucional es especialmente importante para mejorar la coherencia de los programas y acciones.

Así como una nación no puede ser competitiva y productiva en todo, tampoco todos los municipios ni toda una nación puede internacionalizarse y avanzar 
Política municipal para el desarrollo de la Micro, Pequeña y Mediana Empresa

Tarapuez Chamorro, Edwin

simultáneamente en la globalización. Por ello debe buscarse la vinculación al mercado mundial por medio de los municipios y preferiblemente a través de los clusters - cadenas productivas identificadas en los estudios realizados por la Cámara de Comercio de Pasto.

La revolución municipal y su modernización, que no necesariamente es la del Estado central, debe garantizar, dentro de su nuevo papel, la seguridad local para aprovechar las ventajas de la mundialización. El Estado municipal debe internacionalizarse, es decir, pensar globalmente desde lo local.

Conviene no caer en reduccionismos extremos que plantean que el Municipio puede hacerlo todo, que las fallas burocráticas son más importantes que las del mercado y que por tanto no conviene hacer nada. La capacidad administrativa y la autonomía del gobierno municipal no son datos exógenos, sino que pueden ser modificados por las propias políticas locales. Nuevamente, ello requiere de una gran voluntad política por parte de los dirigentes municipales.

Formular una política municipal de desarrollo empresarial es una cosa y poder asegurar la intervención del gobierno local que ella requiere es otra. Esta diferencia no tiene que ver con preferencias personales por más o menos presencia del Estado, porque ella vale para todas las políticas, desde las que requieren una mínima intervención pública hasta las que exigen que esta sea muy importante.

Para el empresario el desafío de una política productiva para el desarrollo, competitividad, promoción y fortalecimiento de las MIPYMES del municipio consiste en desarrollar, en el marco de una nueva cultura productiva, una actitud más comprometida y participativa. También implica el ingreso a un universo cognoscitivo hasta ahora inédito para muchas personas de negocios.

La nueva dinámica regional no puede depender solamente de la reorientación de las políticas del gobierno nacional y local. Los planes departamentales y municipales de desarrollo deben traspasar la limitada proyección en el tiempo. Dichos planes deben tener un mayor contenido estratégico de largo plazo y una mejor y mayor vinculación de las propuestas e iniciativas empresariales.

Así mismo no puede perderse de vista la necesidad ineludible de construir una representación gremial local que trascienda la empresa individual y posicione el punto de vista empresarial a nivel gubernamental. De igual forma, se requiere también que los empresarios, por intermedio de los gremios de la producción, dejen de insistir en pequeños privilegios y medidas de corto alcance por parte del gobierno municipal y concentren toda su atención en las cadenas productivas que harán posible el "nuevo" modelo de desarrollo.

\section{Bibliografía citada}

Asociación Chilena de Municipalidades (1995). El desarrollo económico local. Fundación Fiedrich Ebert. Santiago de Chile.

Boisier, Sergio (1996). La modernización del Estado: una mirada desde las regiones. Revoluciones, reformas, objetivos nacionales y el papel del territorio. En: Medina, Javier y Vare- 
la, Edgar (Compiladores). Globalización y gestión del desarrollo regional. Editorial Universidad del Valle. Cali.

Gonzalez, Pedro Javier (1998). La política industrial en la era de la globalización. Revista Comercio Exterior. Vol. 48, Núm. 7. México, Julio.

León, Nhora (1997). Conceptos, estrategias y gestión del desarrollo local. En: Varios Autores. Análisis regional y empleo. Un enfoque multidisciplinario. Ministerio de Trabajo, Universidad Nacional, CID. Santafé de Bogotá. pp. $17-62$.

Molina, Iván (1997). Nueva regionalización mundial, desarrollo local y gobemabilidad. Revista Comercio Exterior. Vol. 47. Núm. 11. México. Noviembre. pp. 929-942.

Pinto, Juan Alfredo y Suárez, Fabiola (1999). Política de talento humano para la Pyme en Colombia. En: Varios Auto- res. Desarrollo de la pequeña y mediana empresa en Colombia. BIDDNP-ACOPI. Santafé de Bogotá. pp. 113-139.

Porter, Michael (1991). La ventaja competitiva de las naciones. Ediciones Vergara. Buenos Aires.

Ramírez, Miguel Ángel (1997). Crecimiento o Desarrollo en América Latina: una historia en construcción. Revista Comercio Exterior. Vol. 47. Núm. 6. México. Junio. pp. 473-479.

Rangel Suárez, Alfredo (1993). El desarrollo regional. ESAP. Santafé de Bogotá.

Sili, Marcelo (1997). La gestión empresarial en el desarrollo regional de América Latina. Revista Comercio Exterior. Vol. 47, Núm. 6. México, junio. pp. 460-465.

Varela, Rodrigo (1998). Innovación empresarial. Un nuevo enfoque de desarroIlo. ICESI. Santiago de Cali. 